\title{
Acquisition of English Prepositions among Malaysian Learners: A Case Study
}

\author{
Beena Sudhakaran \\ ${ }^{1}$ English Language Department, Centre for Languages and Pre-University Academic Development (CELPAD), \\ International Islamic University Malaysia, Malaysia \\ Correspondence: Beena Sudhakaran, English Language Department, CELPAD, International Islamic University \\ Malaysia, Jalan University, Petaling Jaya, Selangor, Malaysia. E-mail: beena@iium.edu.my
}

Received: February 23, 2015 Accepted: March 20, 2015 Online Published: May 30, 2015

doi:10.5539/ijel.v5n3p1 URL: http://dx.doi.org/10.5539/ijel.v5n3p1

\begin{abstract}
Educationists are often in a predicament as to whether grammar should be taught formally, or whether it can be deliberately learned. This question is especially pertinent in Malaysia where there has been a general deterioration of grammar skills among English as a second language (ESL) learner. A prospective case study was carried out on seven Malay students from the International Islamic University Malaysia. The study sought to determine the extent to which students acquired English prepositions in the naturalistic setting in the written mode, the different types of errors, the use of alternative locative frames, and whether there was a specific pattern in the learning of prepositions. The study used writing tasks where students were required to write essays as well as make journal entries. Data was collected at six monthly intervals over three years. An analysis of students' use of prepositions was carried out to monitor progress. It was found that most subjects had improvements in their use of prepositions, with more errors of commission than omission. One of the most common errors was the unnecessary use of the phrase involving a preposition, 'for me'. Persistent errors could arise due to incomplete linguistic rule formation and transfer from the students' first language (L1). There were also instances of other words like adverbs being used instead of prepositions. The best improvement was seen in the prepositions 'for', 'in' and 'about'. These findings necessitate the need for corrective feedback on errors, and for grammar instruction to be compatible with the natural processes of acquisition.
\end{abstract}

Keywords: natural, acquisition, grammar, teaching, prepositions

\section{Introduction}

\subsection{Prepositions in General}

In English grammar, one of the most perplexing systems is the use of prepositions. The preposition says something about where a thing is (location) or moves (direction), in relation to a point of reference or landmark. Gass and Selinker (2001) contend that prepositions are among the most difficult items to master in a second language (L2). To compound the problem, some prepositions are roughly synonymous with others: they seem to have a relational meaning and this can cause difficulty to L2 speakers. Lindstromberg (1991) says that prepositions are simple, but sometimes, proper use and placing of prepositions pose a problem. The same form of prepositions may carry different meanings in different contexts. It has also been found that the higher the proficiency in L2, the better the acquisition of the language (Zhang \& Widyastuti, 2010). Sinclair (1991) points out that most sentences in English include a preposition, with more than 100 prepositions in the English language. One of the most common errors that people learning English make is the use of the wrong preposition. Gyori (2005) indicates that functional elements like prepositions are general categorizations of relations between non-linguistic phenomena as perceived by people. He suggests that many prepositions categorise recurring patterns in our experience. Lindstromberg (1996) points out that prepositions are likely to have a few related literal meanings. There is a tendency to adopt one of these meanings as a psychological prototype, being regarded as a sort of best example. Apart from this, it has been claimed that some of the literal meanings of the preposition, more so the prototypical meaning, are modified with the use of metaphors to create a whole new set of meanings. Galleguillos (2013) found that students used several strategies to acquire prepositions like 'in', 'on', and 'at', like overgeneralization of basic uses, inference, application of rules, mental images, among others. Jayoung (2014) found that enhanced extensive reading can effectively contribute to EFL secondary school students' incidental acquisition of English 
prepositions.

Additionally, there may be differences in the prepositions of the students' first language (L1) and the L2. A non-native English speaker thus finds it difficult to differentiate between how a particular preposition in English functions, and what it really means in context. Boquist (2009) contends that difficulties in acquiring prepositions occur because second language acquisition creates certain clash points, and prepositions constitute part of these clash points.

Mohideen (1991) observed that similar errors in the use of prepositions occur among students at all levels, and also among teachers and other graduates. These universal errors are in three main areas: i) errors of omission, where the right preposition is not being used in an obligatory context; ii) errors of commission, where a preposition is used when there is no obligatory context; and iii) misuse of prepositions, that is, an incorrect preposition is used, thus creating an incoherent message.

Despite these difficulties faced with prepositions and their prominent role in the semantics of English, Lindstromberg (1996) points out that remarkably little space is devoted to prepositions in English language teaching course books produced in the UK or the USA. Reference grammars, practice grammars, and supplementary books have only small sections on prepositions. The assumption of both English Language teaching (ELT) grammarians and lexicographers seem to be that the semantics of prepositions are too complex and unsystematic to warrant thorough investigation, either in or out of the classroom. Rather, prepositions are largely to be learned in the form of narrow context by narrow context, often phrase by phrase.

\subsection{Teaching of Prepositions}

Lindstromberg (1991) contends that prepositions are sometimes taught as if their meanings are unpredictable and highly idiomatic, so that the number of vocabulary items that students have to learn is greatly increased. Consequently, students may get discouraged since they may get the impression that the English preposition system is disorganized. Takahashi (1969) claims that many teachers who teach English as a Second Language (ESL), do not explain functions logically nor provide a conceptual guide. Rather, many teachers contend that the functions and usage of prepositions involve intuition. This may prevent many ESL students from mastering prepositions, with many learners memorising or using analogy and inference to learn prepositions. It has also been found that different tasks (dictation, individual reconstruction and collaborative reconstruction) results in different degrees of acquisition (Sharifalnasab \& Fotovatnia, 2013).

Lindstromberg (1991) goes on to elaborate that for many experienced teachers, the wrong understanding of prepositions may be the main source of difficulties. The preposition is one of the syntactic or grammatical categories that always creates some degree of confusion in many of the non-native English speakers who study the language as an L2. Basically the confusion is due to the gap between the set of rules which one learns in the classroom and the actual use of it by native English speakers, where native speakers may not even know the rules, but learn through listening and practising.

Since the preposition system is deemed problematic to most non-native learners of the English language, with a lack of definite rules, and with the lack of emphasis on prepositions, the question arises as to how successful ESL students have been in acquiring prepositions on their own in the naturalistic environment. Thus, if indeed these students have acquired these prepositions, then they would be able to use them effectively in their everyday communication and in their academic work.

\subsection{Teaching of English in Malaysia}

In the Commonwealth countries including Malaysia, English was an extremely important language before attaining independence. In Malaysia, English was the medium of instruction and the language of administration in the colonial days till independence in 1957, and for about a decade after that. However, with the implementation of the National Language Policy in 1967, the English language was gradually phased out as the main medium of instruction in primary, secondary and tertiary education in the country. The national language, Bahasa Malaysia $(\mathrm{BM})$, supplanted English as the premier language of the nation. This reduction of the importance in the use of the English language had implications for the ESL classroom situation in Malaysia. There was a change in emphasis of the curriculum, so that instead of teaching notions and functions of grammar, the communicative approach was introduced wherein grammar was integrated with the literary skills of listening, speaking, reading and writing. This resulted in a deterioration of students' grammar skills, especially in the use of grammatical items. Mohideen (1991) has listed grammar items that pose persistent difficulty to Malaysian students, one of them being the preposition system in the English language. 


\subsection{Purpose of the Study}

This study focuses on the ultimate attainment of mastering prepositions by Malaysian ESL learners, in the absence of formal teaching focused on prepositions. The objectives of the study are as follows:

1) It aimed to look at the degree to which learners acquire prepositions in the writing mode in a naturalistic setting, in the absence of formal instruction.

2) It was hoped to identify the most common source of errors, be it omission of prepositions or errors of commission, i.e. insertion of wrong prepositions. This would determine the type of errors made, focusing on situations or instances where learners do not use the preposition when it rightly should have been used (errors of omission), as well as instances where the wrong preposition is used (preposition errors). This would also include situations where a preposition is used when it is not necessary (errors of commission). If the learners use alternative words instead of prepositions, then these too will be identified.

3) In addition, it would also identify the prepositions that learners have the most difficulty with, as opposed to those that they use comfortably, and will determine whether or not there is a definite pattern in the acquisition of prepositions over the period of study.

\subsection{Area of Study}

This study focused on determining the extent of naturalistic acquisition of prepositions without formal instruction, by analyzing the different types of errors that students make in written production.

James (1998) indicates that there are four major categories of errors: interlingual, intralingual, induced, and communication-strategy based errors. Interlingual errors arise from the effects of the mother tongue in the process of acquisition of the target language, there being transfer from the mother tongue (L1 transfer). Apart from resorting to L1 transfer, learners would go about learning the needed item either by using learning strategies, or by recourse to communication strategies, errors from these being referred to as intralingual errors. Induced errors, on the other hand, refer to errors arising from being misled in the classroom by the ways in which teachers give definitions, examples, explanations, and arrange practice opportunities. Finally, communication strategy-based is where the learner assumes that if he can say X in L2, then he should be able to say $\mathrm{Y}$ as well, or where the learner expresses a concept by alluding to it rather than by direct reference.

Ellis (1994) elaborates that in the natural settings be it the street, market or workplace, the learning of the target language is through observation and direct interaction with speakers of that language. In this situation, the learner gives scant attention to mastering the grammatical aspects of the language. Ellis (1997) suggests that investigation of L2 acquisition could focus on the types of errors made by learners, and how these errors change over time. Apart from this, it can identify developmental patterns by describing the stages in the acquisition of specific grammatical features.

Ellis (1997) also suggests that examining the developmental patterns among learners would allow a study of the universality of L2 acquisition. He elucidates that there is a definite order of acquisition of specific grammatical structures, based on how accurately each one of them is used by the learners. With respect to errors, one type of error may alternate with another, since learner language is systematic, yet at the same time variable, so that at a particular stage of development, learners may use one form, and sometimes another.

\section{Method}

\subsection{Study Type}

This research used a longitudinal case study approach that entailed observing the development of linguistic performance over a span of time with subsequent statistical analysis. The analysis of their written work was carried out to determine whether there was any change in the use of English prepositions. This technique is in accordance with Tobin's (1990) sign-oriented theory which investigates specific use of concrete language data obtained from written discourse in different linguistic and situational contexts.

\subsection{Study Sample}

The sample for this study was seven pre-matriculation students from the International Islamic University Malaysia (IIUM). At the time of commencement of the study, these students were studying English prior to taking up their respective majors. Most of them had planned to pursue professional courses. Their classes were co-educational and the average age of the students was 19 years. Based on baseline data, their proficiency in the use of prepositions ranged from $61.1 \%$ to $71.6 \%$.

All the seven subjects of this study were Malay students who had joined the university from Malaysian public 
schools (where the medium of instruction is Malay). Malay students were selected as they form the majority of the population at the tertiary institution (Matriculation Centre, International Islamic University Malaysia (IIUM)) where the study was conducted.

These students were previously taught the English language during their eleven years of schooling before they joined the Matriculation programme at IIUM. The medium of instruction in IIUM is English, so students have opportunities to interact in English with international students, especially when they move to the main campus to pursue their majors, on completion of their matriculation programme. These international students are second language learners with a variety of L1 backgrounds, having medium to high levels of proficiency in English, with all being able to converse well in English.

For the duration of eight months in the Matriculation course, they were taught grammar in an integrated manner with listening, speaking, reading and writing skills. However, they were not formally taught prepositions, so that any improvement in skills in the use of prepositions would have been achieved through their own efforts in reading and communication in English with international students, lecturers and others.

When admitted into this programme in IIUM, to determine their proficiency level in English, students have to sit for an entrance examination conducted by the university - the English Placement Test (EPT). Based on their performance in this test, they are placed into three groups - low, medium and high. The groups of students selected for this study were randomly sampled from the medium and high competency levels to ensure at least a satisfactory level of competence in the English language.

\subsection{Study Instruments}

To elicit information on preposition use from the students, students were asked to write five essays as well as fifteen journal entries each time. These tasks were conducted in five phases - an initial round, followed by subsequent rounds of the tasks at six monthly intervals. At each phase, the researcher obtained data on the tasks in the form of individual pieces of information obtained for analysis of each task. Students had to write an essay of about 400 words. On the first occasion, they were allowed to choose their own topic, and were asked to write on the same topic at subsequent times. However, they were not given any prior warning of the task until they turned up, to forestall any no prior formal preparation.

\subsection{Data Analysis}

The essays were analyzed for errors related to the use of prepositions in relation to the objectives of the study. Journal writing had been carried out routinely in class as part of their writing assignments. These were generally regarded as a means by which students were able to communicate with teachers on confidential issues, as well as to encourage students who were reluctant to speak in class to communicate freely with teachers. It was impressed upon the students that journal writing was actually free writing. This was to ensure that students paid more attention to the content, rather than on writing style or grammar. Consequently, it was hoped that the language used in these journals would be informal, and closer to spontaneous speech. This would enable information on the students' use of prepositions to be obtained in as natural a setting as possible, without the students consciously making efforts to avoid errors or deliberately write in a formal manner. It must be pointed out that students were not informed of the focus of the study, so that they would not pay any special attention to any aspect of their tasks.

The students' use of prepositions in the essays and journals was analysed to determine whether or not there was any change in their competency level in the use of prepositions based on whether or not there were differences in the number of errors. A frequency count of the various instances where prepositions were used, both correctly and incorrectly, was carried out. The data was sorted into coherent and incoherent messages. The correct use of prepositions by a student was viewed as an indication of capability of conveying a coherent message, which also provided an indication of the student's proficiency in the use of prepositions. On the other hand, if the student had made errors, the message became incoherent. These errors committed by students in the use of prepositions were classified as errors of commission, that is, either a wrong preposition had been used, or a preposition had been used in a situation where it was not needed. The other type of error was defined as errors of omission where a preposition had not been inserted when it rightly should have been used.

Analysis was also made to determine whether there was a specific pattern in the acquisition of prepositions, focusing mainly on the more commonly used prepositions. Apart from this, the data was analysed to determine whether there were alternative locative forms used by students, and if so, these were isolated and analysed for the occurrence of definite patterns. Attempts were also made to identify the rationale or reasons for the various types of errors made by students. 


\section{Results}

To determine whether the number of prepositions was dependent on the number of words used, a word count was made of all journal entries for all the seven students. Subsequently, the numbers of prepositions used were compared to the word counts, and the percentages calculated. It was found that the percentages of prepositions were independent of the word counts - there were some students who had high word counts, but with low numbers of prepositions used. Conversely, there were others with low word counts but with high percentages of prepositions used, the percentage of prepositions used ranging from 5.2 to $15.4 \%$, with the percentage of coherent prepositions ranging from 4.3 to $14 \%$. No definite pattern could be established between the percentages of prepositions compared to the numbers of words, or the proportion of coherent messages compared with word counts.

Initially, performances of students for individual prepositions over the study period were analysed. However, since the level of errors in prepositions in general was small, it became even smaller when considering individual prepositions. As such, it was difficult to draw specific conclusions on the extent to which particular prepositions were acquired by each student.

\subsection{Levels of Errors in Prepositions}

From an overall perspective, there were diminishing numbers of errors over time. Since the topics for the writing tasks were the same for all the data sets, and there were no specific alternative locative structures, it can be concluded that there was improvement among all students. However, the degree of improvement differed with different students. Most students showed a high percentage of errors in the first data set as seen in Table 1 below:

Table 1. Average levels of errors in use of prepositions

\begin{tabular}{cccccc}
\hline \multirow{2}{*}{ Student } & \multicolumn{5}{c}{ Percentage of errors $(\%)$} \\
\cline { 2 - 6 } & $1^{\text {st }}$ phase & $2^{\text {nd }}$ phase & $3^{\text {rd }}$ phase & $4^{\text {th }}$ phase & $5^{\text {th }}$ phase \\
\hline 1 & 18 & 12.3 & 9.2 & 9.9 & 8.7 \\
2 & 9.7 & 9.6 & 13 & 6 & 12.4 \\
3 & 12.6 & 5.6 & 4.2 & 6.1 & 5.5 \\
4 & 17.5 & 14.8 & 19.1 & 20.4 & 13.6 \\
5 & 21.9 & 18.7 & 14.5 & 13.1 & 8.5 \\
6 & 18.4 & 16.4 & 10.3 & 18.1 & 10 \\
7 & 20.6 & 15.5 & 11.8 & 14.8 & 11.9 \\
\hline
\end{tabular}

It can be seen that student 5 had shown the most improvement followed by student 1 . On the other hand, Student 2 had not shown any improvement at all, while Student 4 had shown only minimal improvement. The trends in errors for these students are depicted graphically in Chart 1 below. 


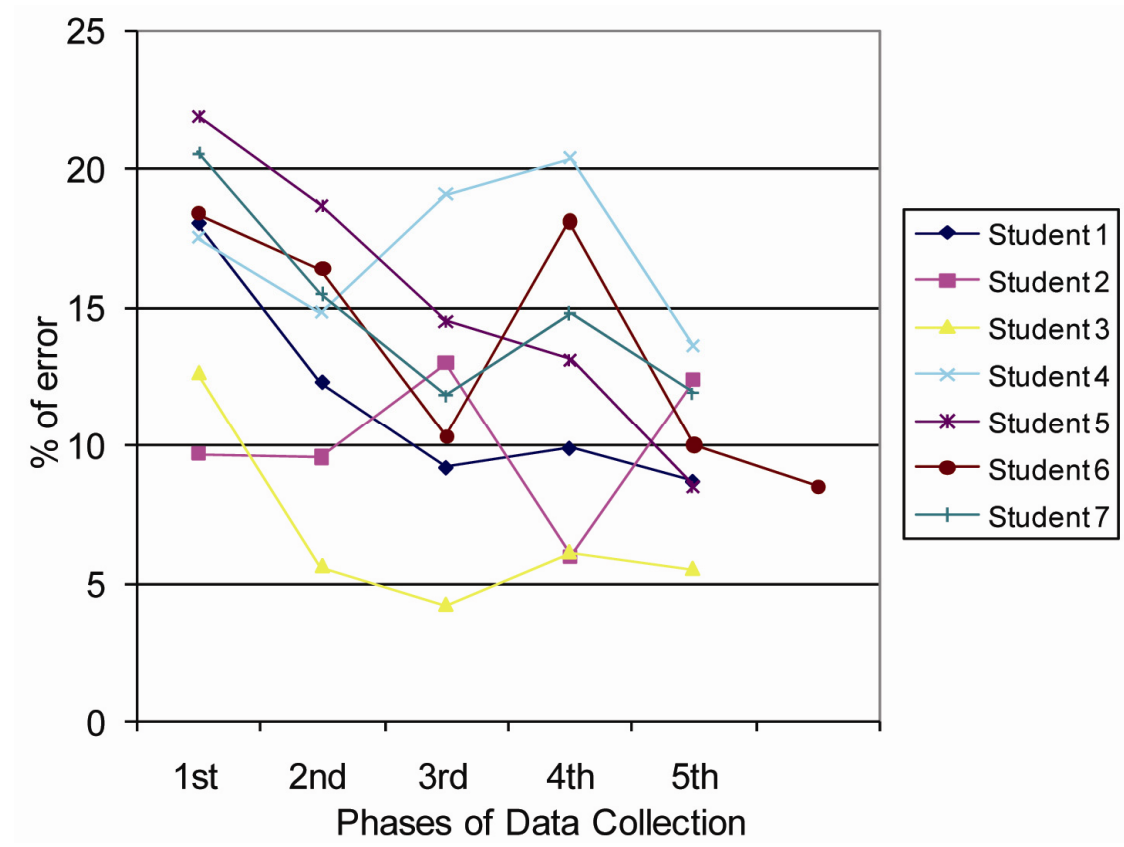

Figure 1. Progress of students' performances in use of prepositions over study period

\subsection{Types of Errors in the Use of Prepositions}

From an overall perspective, again, all students had committed more errors of commission as compared to errors of omission. The levels of errors for all five sets of data for essay and journal writing, are shown in table 2 below:

Table 2. Levels of errors of commission and omission in the use of prepositions

\begin{tabular}{ccc}
\hline Name of student & Errors of Commission (\%) & Errors of Omission (\%) \\
\hline Student 1 & 14.3 & 3.5 \\
Student 2 & 11.0 & 2.3 \\
Student 3 & 7.7 & 1.2 \\
Student 4 & 16.4 & 2.2 \\
Student 5 & 17.2 & 0.7 \\
Student 6 & 13.7 & 1.8 \\
Student 7 & 17.1 & 1.4 \\
\hline
\end{tabular}

Student 3 had a very low level of errors of commission (7.7\%) while Students 5 and 7 had high levels of errors (17.2\% and $17.1 \%$ respectively). It can be seen that Student 3 with a low level of errors of commission (7.7\%), was one of those who showed considerable improvement in the use of prepositions over the study period. Students 5 and 7 who had the highest levels of errors, also showed improvement in the use of prepositions.

\subsection{Analysis of Individual Prepositions}

The commonly used prepositions during the study period are shown in Table 3 below.

Table 3. Commonly used prepositions

\begin{tabular}{lcc}
\hline No. & Preposition & Total number used \\
\hline 1 & to & 1354 \\
2 & at & 1239 \\
3 & in & 1085 \\
4 & for & 909 \\
5 & of & 792 \\
6 & with & 456 \\
\hline
\end{tabular}


It can be seen the three most commonly used prepositions in this study are 'to', 'at' and 'in', with the preposition 'to' being used almost three times as much as the least commonly used preposition, 'with'. Next, the levels of errors in the use of individual prepositions were analysed. As can be seen from Table 4 below, there was an improvement in the performance of the students in the use of most of the prepositions. If the trends of the performances in the various prepositions are compared, the best improvements were seen with the preposition 'in', followed by 'to' and 'of'. There was also improvement in the use of the preposition 'for', with some improvement being seen as well with the use of the preposition 'at'. However, for the preposition 'with' there was only minimal improvement as seen in Table 4 and the line graph in figure below.

Table 4. Levels of errors in the use of commonly used prepositions

\begin{tabular}{lccccc}
\hline \multirow{2}{*}{ Preposition } & \multicolumn{5}{c}{ Percentage of errors $(\%)$} \\
\cline { 2 - 5 } & $1^{\text {st }}$ phase & $2^{\text {nd }}$ phase & $3^{\text {rd }}$ phase & $4^{\text {th }}$ phase & $5^{\text {th }}$ phase \\
\hline in & 21.4 & 25.3 & 11.3 & 15.4 & 12.0 \\
for & 25.3 & 32.8 & 26.2 & 26.4 & 19.7 \\
of & 18.8 & 9.1 & 6.8 & 8.0 & 5.9 \\
at & 13.7 & 16.7 & 13.9 & 10.7 & 10.9 \\
with & 17.0 & 10.7 & 12.2 & 9.9 & 15.7 \\
to & 19.4 & 9.3 & 8.0 & 6.0 & 7.4 \\
\hline
\end{tabular}

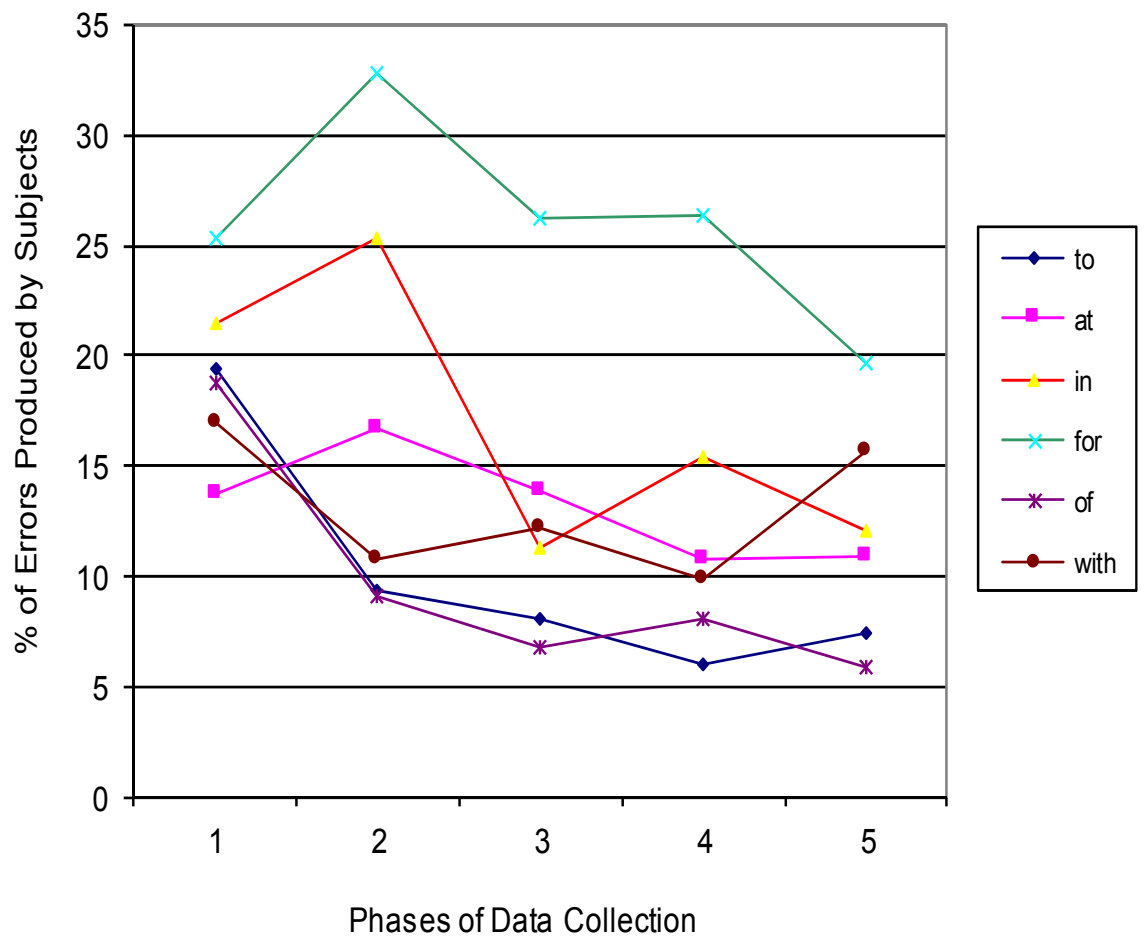

Figure 2. Levels of errors in commonly used prepositions

\section{Discussion}

There could be many reasons for these differing degrees of improvement among students. One could be that these students confine themselves to their own ethnic group where they resort to their mother tongue as the language of communication. Their lack of contact with foreign students may have deprived them of opportunities to practice the use of the English language. Bremer et al. (1996) argue that the actual exposure to the target language may be less than expected, because many variables can limit the quantity and quality of input of the target language. They did not find that naturalistic contexts gave learners more opportunities for input, since in their study too, many subjects did not use the target language with colleagues, friends and relatives.

Many of the studies on second language acquisition in the naturalistic setting (for example, Schmidt, 1983, Norton, 
2000; Goldstein, 2001) were conducted with immigrants, or in the case of Schmidt (1983) a foreigner in an English speaking country. Many subjects in these studies did not have much interaction with native speakers, nor were they given the space needed to develop competence in the target language. They merely needed mastery of the language for communication purposes (Bremer et al., 1996). Norton (2000) argued that subjects should also possess additional interest to develop mastery of the language rather than just gain communicative skills. The students in this study, on the other hand, were in the academic environment, so apart from communicating, they had to interact and develop competence in the English language.

The students' culture may also have contributed to the errors produced by the subjects. James (1998) points out that silence (situations where learners do not speak or write) can be due to what he terms as 'cultural silence' where people are silent by nature as opposed to the silence of ignorance, citing Finnish and Japanese learners as examples. A similar situation exists among Malay students who do not usually participate actively in discussions (Mohideen, 1991).

Another reason for the differences in performances among students could be that students may be at different stages of learning, some having completed the learning process, while others may be still in the midst of it. James (1998) suggests that learning is a two-stage process. The first is the learning stage where learners accumulate good target language-like repertoires that they did not possess before. However, they do not immediately reject the wrong forms they had been using all along, prior to learning the right ones. Consequently, the incorrect and right forms co-exist side-by-side for a while, when it is said that the interlanguage is variable. The second stage involves removing the old and wrong forms, so that only the correct and good forms are left with the learners.

Apart from this, as mentioned in the theoretical framework, Tobin (1990) described the mechanism of development of highly polysemous words, illustrating how the prepositions may begin as 'locatives', and then extend metaphorically from concrete spatial messages to the more abstract area of 'temporal' messages, and subsequently to the more abstract area of 'existential' messages, until it can reach a point of being 'nominalised', or made into adjectives.

With respect to types of errors, there was much more variation in the levels of errors of commission, indicating that they are in different stages of development. Hence, this study supports the variability hypothesis (Ellis, 1997). Another possible reason for a high level of errors is that students are engaging in learning strategies like false analogy, mis-analysis and incomplete rule application, in line with James' (1998) learning strategies.

The data on differing levels of errors in different prepositions is in line with Ellis' (1997) work on developmental patterns which suggested that some of the linguistic features are easier to learn than others. In addition, learners also employ various learning strategies to develop their interlanguages (James, 1998).

It can be concluded that most of the subjects of the study showed improvements in their use of prepositions over the period of study. However, the degree of improvement was different with different students. In addition, while their competency levels had improved, this was still not of a very high level, and fell short of the competency level that would be achieved by native speakers of English.

With respect to the different types of errors, the subjects of the study produced more errors of commission than errors of omission. This could be due to students' use of different learning strategies. However, again the subjects differed in their level of errors in production. With respect to different types of errors in the subjects' use of alternative locative frames, one of the most common errors made by most of the students was the use of the phrase involving a preposition, 'for me', in situations where it was not suitable or relevant. The L1 transfer strategy was also seen in many students' production of the L2. There were also instances of other words such as adverbs being used instead of prepositions.

Considering the most commonly used prepositions, students had the best results with the prepositions 'to, 'of' and 'in'. This is in line with Ellis's (1997) finding that students find some prepositions easier than others and consequently acquired them earlier (Ellis, 1997).

In the analysis of the performances of individual students, learners vary in their acquisition rates. These individual variations were in line with observations by other SLA researchers (Al-Qudah, 2013; Mitchell \& Myles, 2004; Archibald, 1996). However, there were instances where there were no errors of commission and one error of omission in certain sets of data, so that it appeared that errors of omission were produced at a higher level. This indicates staged development, another feature of SLA (Mitchell \& Myles, 2004). Apart from this, since the actual numbers of errors of omission were low for most students, improvement in their performances over the study period could not always be demonstrated clearly. In addition, the prepositions most frequently used by students also varied, as did alternative locative frames, and prepositions with which students made most errors. 
It needs also to be pointed out that the level of competence in the use of prepositions may not also be representative of the competence in that language. This means that even if a subject has a high level of competence in the use of prepositions, he may not have a high level of competence in that language. As stated by Ellis (1997) many researchers found that there were particular types of grammatical items including prepositions, which learners failed to acquire. It was also found that even in advanced ESL learners, errors were morphological rather than syntactic, indicating that learners were not competent in the use of grammar. Ellis also suggested that saliency or the ease with which learners were able to perceive grammatical features in input may affect acquisition; the grammatical features that are salient were acquired preference to less salient ones. Apart from this, frequency with which different items appear in the input may have a bearing on acquisition, the more frequently appearing items being acquired earlier. Ellis (1997) further suggested that since some grammatical features are acquired naturally, while others are not, there may be need for form-focused instruction to assist learners in those areas where difficulties are faced.

The findings of this research appear to fit the current recommendations of grammar teaching, especially those postulated by Ellis (1997) and others (Pavesi, 1987; Norton, 2000). The general consensus is that it may be beneficial to teach grammar, but it should be taught in a way that is compatible with the natural processes of acquisition. This teaching should focus on developing implicit knowledge of the L2, although explicit knowledge should not be neglected. The results also indicate that there is a need to equip teachers with special skills to be able to teach prepositions. One suggestion would be to formally teach such grammatical items that students may not or have difficulty in acquiring naturally. For example, Ellis (1997) suggests that instruction aimed at marked grammatical properties will help to promote more efficient learning since it will assist learners acquire features that they may not acquire naturally. Hulstijn and De Graaf (1994) recommend that grammar instruction focus on complex rules, since they imply that simple rules are salient in the input and thus can be learnt implicitly. Another area that may be difficult to acquire naturally is where certain target language structures differ from the learner's L1 (White, 1991). Apart from this, rather than the traditional teaching of grammar focussing on the language itself, there should be more effective strategies for teaching the preposition system. Teachers would then have to take cognisance of the most comprehensive approach in the teaching of the English preposition system.

To be effective, language teaching requires extensive L2 input, maximizing the use of the L2 in the classroom, so that the L2 becomes the medium as well as the object of instruction. Another requirement is to ensure that learners are developmentally ready to acquire prepositions. In addition, individual differences in learners have to be taken into account as well. It needs to be borne in mind that there is also considerable variability in the rate of learning and in the ultimate level of achievement.

\section{References}

Al-Qudah, A. K. (2013). Acquisition of Some Selected Prepositions of Time by English Major Undergraduates at Balqa Applied University in Jordan. English Language Teaching, 6(9).

Boquist, P. (2009). The Second Language Acquisition of English Prepositions. Liberty University (unpublished thesis).

Bremer, K., Broeder, P., Roberts, C., Simonet, M., \& Vasseur, M. T. (1996). Achieving understanding: Discourse in intercultural encounters. London: Longman.

Ellis, R. (1994). The study of second language acquisition. Oxford: Oxford University Press.

Ellis, R. (1997). Second Language Acquisition. Oxford: Oxford University Press.

Galleguillos, C. F. (2013). The acquisition of English prepositions among Chilean EFL learners. University of Chile (Unpublished thesis).

Gass, S. M., \& Selinker, L. (2001). Second language acquisition: An introductory course (2nd ed.). Mahwah, NJ: Lawrence Erlbaum Associates Inc.

Goldstein, T. (2001). Researching women's language practices in multilingual workplaces. In A. Pavlenko, A. Blackledge, I. Piller, \& M. Teusch-Dwyer (Eds.), Multilingualism, second language acquisition, and gender (pp. 77-101). New York: Mouston de Gruyter. http://dx.doi.org/10.1515/9783110889406.77

Gyori, G. (2005). The adaptive nature of "meaning as understanding". Acta Linguistic Hungarian, 52(2-3), 199-220. http://dx.doi.org/10.1556/ALing.52.2005.2-3.4

Hulstijn, J., \& De Graaf, R. (1994). Under what conditions does explicit knowledge of a second languagefacilitate the acquisition of implicit knowledge? A research proposal. AILA Review, 11, 97-112.

James, C. (1998). Errors in language learning and use. Exploring error analysis. London: Longman. 
Lindstromberg, S. (1991). (Re) teaching Prepositions. English Teaching Forum, 29, 47-50.

Lindstromberg, S. (1996). Prepositions: Meaning and Method. ELT Journal, Vl-50, 225-236. http://dx.doi.org/10.1093/elt/50.3.225

Mitchell, R., \& Myles, F. (2004). Second Language Learning Theories. London: Arnold Hodder.

Mohideen bin Mohamed Ali Haja. (1991). An error analysis in the written English of Malay students at pre-university level. University of Wales, Cardiff, Unpublished doctorial thesis.

Norton, B. (2000). Identity in language learning: Gender, ethnicity and educational change. London: Longman.

Pavesi, M. (1987). Variability and Systematicity in the Acquisition of Spatial Prepositions. In R. Ellis (Ed.), Second Language Acquisition in Context. Prentice Hall International (U.K.) Ltd.

Schmidt, R. (1983). Interaction, acculturation, the acquisition of communicative competence. In N. Wolfson \& E. Judd (Eds.), Sociolinguistics and TESOL (pp. 137-174). Rowley, MA: Newbury House.

Sharifalnasab, A., \& Fotovatnia, Z. (2013). The Effect of Different Tasks on L2 Learners' Acquisition of Grammar. Journal of Language Teaching and Research, 4(2), 386-391. http://dx.doi.org/10.4304/jltr.4.2.386-391

Sinclair, J. (Ed.). (1991). Collins cobuild English guides: Prepositions. London: Harper Collins.

Song, J. (2014). EFL Learners' Incidental Acquisition of English Prepositions through Enhanced Extensive Reading Instruction. RELC Journal, 45(1), 67-84. http://dx.doi.org/10.1177/0033688214522623

Takahashi, G. (1969). Perception of space and the function of certain English prepositions. Language Learning 19 , 217-234. http://dx.doi.org/10.1111/j.1467-1770.1969.tb00464.x

Tobin, Y. (1990). Semiotics and Linguistics. London \& New York: Longman.

White, L. (1991). Argument structure in second language acquisition. French Language Research, 7, 133-161. http://dx.doi.org/10.1017/s0959269500000983

Zhang, Y., \& Widyastuti, I. (2010). Acquisition of L2 English morphology: A family case study. Australian Review of Applied Linguistics, 33(3). http://dx.doi.org/10.2104/aral1029

\section{Copyrights}

Copyright for this article is retained by the author(s), with first publication rights granted to the journal.

This is an open-access article distributed under the terms and conditions of the Creative Commons Attribution license (http://creativecommons.org/licenses/by/3.0/). 